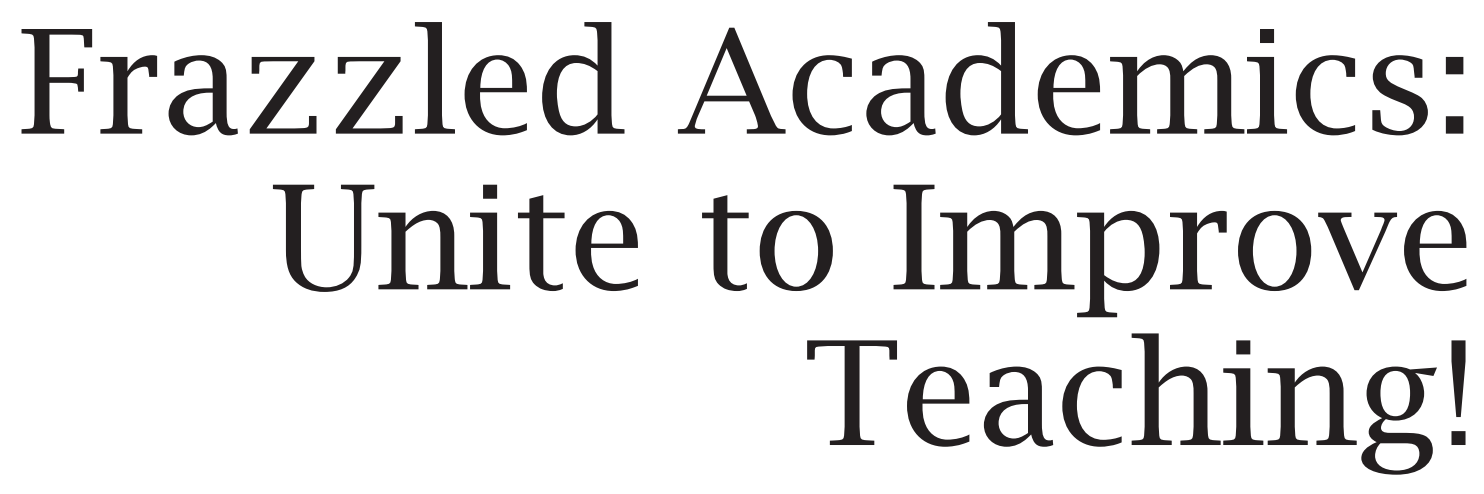

Sybilla Beckmann and Jacob Hicks

Are you this frazzled academic who cares about education?

Frazzled academic: "I put the last paper on top of the stack after recording grades on my latest test. Now I only have fifteen minutes to get to yet another faculty meeting.... I get back to my office and take a breath. My mind wanders to the test. The students could have done better. Their algebra is a mess! Did they learn anything in high school? Did they listen to what I said in class? Though honestly, I know I could be a better teacher; I want to be. But that grant application.... How do I find the time to become a better teacher? And even if I had the time, what would I do to improve?"

How do we become better at teaching? Can we do so without devoting all our time and energy to teaching?

Improving mathematics teaching is a big, important project, and big, important projects usually are not done in isolation. They typically take a community and collective thinking over time. Alone, we are unlikely to continuously polish, refine, and develop our teaching. But what if we had others

Sybilla Beckmann is Josiah Meigs Distinguished Teaching Professor of Mathematics at the University of Georgia. Her email address is sybi11a@math. uga. edu.

Jacob Hicks is a graduate student in mathematics at the University of Georgia. His email address is jhicks@math. uga.edu.

Members of the Editorial Board for Doceamus are: David Bressoud, Roger Howe, Karen King, William McCallum, and Mark Saul.

DOI: http://dx.doi.org/10.1090/noti1130 to encourage, inspire, and build us up? What if we could learn with and from other people who care about mathematics teaching? We need the ongoing support of a community to help us develop our skills and ideas about mathematics teaching. The Mathematics Teaching Community (MTC), online at

https://mathematicsteachingcommunity.
math. uga.edu,

is designed for people who teach mathematics to work together to become better teachers. You can go to the MTC to find out what others are currently thinking. Suppose you are interested in teaching calculus or analysis or in teacher preparation in light of the K-12 Common Core State Standards (CCSS) for Mathematics. Figure 1 shows a few examples of what you will find if you search for "calculus" or "analysis". Figure 2 shows a few submissions under the CCSS tag. You can also browse through the tags. If you cannot find the specific tag, topic, or question for which you are looking, you can post a new submission. If you find something interesting, you can make comments or ask questions.

Your submissions can be about your own classroom practices or about broader issues of mathematics education that affect you. Maybe you are questioning whether we should be teaching related rates in calculus. Others can agree with you or provide a new perspective on why related rates are important. Maybe you have a great idea for teaching optimization problems. Others can read and learn from what you have written. They can ask you questions or bring up ideas you had 


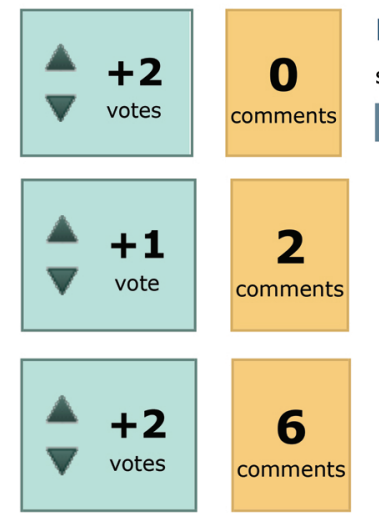

Making Calculus Fun--Optimization Problems

751

submitted 11 months ago by Kate_Thompson (920 points)

optimization word-problems

Conservative forces, work, and German engineering 24 views

commented $\mathbf{4}$ days ago

multivariable-calculus work force conservative-forces

\title{
teaching analysis
}

95 views

submitted $\mathbf{5}$ months ago by Joe Fu

teaching-methods analysis

Figure 1. Some submissions under the "calculus" and "analysis" tags.
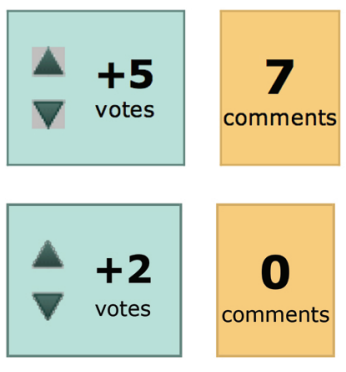

\author{
What is the standard multiplication algorithm? \\ submitted 6 months ago by Sybilla (4,890 points) \\ standard-algorithms mul \\ multiplication \\ What's a math educator to do? Response to
Garfunkel in the Notices of the AMS
submitted 7 months ago by Sybilla
ccss community-of-math-teachers
}

numbers-operations-base-ten

coss algorithm

122 views

Figure 2. Some submissions under the "CCSS" tag.

not considered. You can teach and learn with and from others on the MTC.

On the MTC you can get feedback not just from your immediate colleagues, but from a much broader community of mathematics teachers from kindergarten through college. Hearing from people with different perspectives and being exposed to a diversity of ideas can spark your creativity and help you think about your teaching in new ways.

Frazzled academic: “Cool! But I'm concerned about getting promotions and raises. How can I justify spending time on this?"

By interacting with others on the MTC, you can have impact on teaching beyond your institution. You can share how you have changed your teaching, which could inspire others to change their practice. If you are concerned about $\mathrm{K}-12$ education, you might like to interact with $\mathrm{K}-12$ teachers or with teacher-educators of K-12 teachers.

Your postings and comments on the MTC can earn you reputation points so that you have a tangible measure of your participation in the community. You could refer to your postings, comments, and reputation points to help you demonstrate your contributions to teaching. Perhaps this could even be useful in tenure and promotion.
Frazzled academic: "This sounds great! But what if I get swamped for a few weeks?"

The MTC is forgiving-if you miss a few days because you are busy, it's still there. Unlike an individual blog, it doesn't all depend on you: the discussion can continue and the community as a whole moves forward while you come and go. So why not give it a try?

We have a vision of mathematics teaching as a vibrant profession in which we discuss issues of teaching and learning and build on each other's ideas. We think that mathematics teaching will become stronger if we join together-across all levels - to nurture our profession. There is much room for growth in mathematics teaching and much potential and thinking power that has not yet been tapped. We invite you to visit and look forward to hearing from you on the Mathematics Teaching Community.

\section{Acknowledgments}

We would like to thank Pete Clark and Kate Thompson for commenting on an earlier draft. 